\title{
Fatty-Acid Oxygenation by Fungal Peroxygenases: From Computational Simulations to Preparative Regio- and Stereoselective Epoxidation
}

Martí Municoy, ${ }^{+}$Alejandro González-Benjumea, ${ }^{+}$Juan Carro, ${ }^{+}$Carmen Aranda, Dolores Linde, Chantal Renau-Mínguez, René Ullrich, Martin Hofrichter, Victor Guallar,* Ana Gutiérrez,* and Angel T. Martínez*

Cite This: ACS Catal. 2020, 10, 13584-13595

Read Online

ABSTRACT: Epoxidation of unsaturated fatty acids by unspecific peroxygenases (UPOs) of the best-known long-UPO subfamily, including the Agrocybe aegerita (AaeUPO) and Coprinopsis cinerea enzymes, is reported here. To understand the different oxygenation patterns by members of the long-UPO and short-UPO subfamilies, the latter represented by the Marasmius rotula enzyme (MroUPO), fatty-acid diffusion into their heme pockets was simulated with the adaptive PELE software. Computational results shed light on the inability of AaeUPO to epoxidize oleic acid (C18:1), opposed to MroUPO, due to steric hindrances to harbor (with a good interaction energy) the substrate with

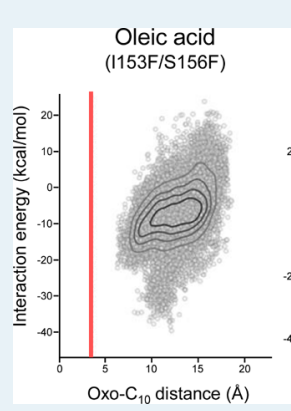
Linoleic acid
(I153F/S156F) a-Linolenic acid the $\Delta 9 \mathrm{C}_{10}$ atom at a catalytically relevant distance $(<3.5 \AA)$ from the oxo group in simulated heme compound-I. However, effective $\alpha$-linolenic acid epoxidation is anticipated because the $\Delta 15 \mathrm{C}_{16}$ atom would attain such a distance in AaeUPO thanks to its more terminal position. The above hypothesis was verified using an engineered MroUPO variant (I153F/S156F) with a narrowed heme access channel mimicking that of AaeUPO. Experimental oxygenation of unsaturated fatty acids by this variant thus resembles that of AaeUPO, including regioselective (from $95 \%$ to $>99 \%$ ) formation of cis,cis-15,16-epoxyoctadeca-9,12-dienoic acid. The nearly complete conversion of $\alpha$-linolenic acid by the two enzymes was transferred to a small preparative scale, the yield of purified product was estimated, its chemical structure analyzed by NMR, and more interestingly, stereoselective production of the $15(R), 16(S)$ enantiomer $(80-83 \%$ ee $)$ assessed by chiral HPLC. This enzymatic synthesis overcomes the unspecificity of chemical epoxidation where the reaction cannot be restricted to the formation of monoepoxides as found during $m$-perchlorobenzoic acid oxidation of $\alpha$-linolenic acid. Moreover, the variant was able to produce the unsaturated dicarboxylic fatty acid, together with subterminal oxygenation products, during partial conversion of oleic acid. These two noteworthy reactions had not been reported for any UPO described to date.

KEYWORDS: computational chemistry, unsaturated fatty acids, oxygenation patterns, regioselective epoxidation, stereoselective epoxidation, Monte Carlo molecular simulations, adaptive-PELE, fungal unspecific peroxygenases

\section{INTRODUCTION}

Together with nonfood carbohydrates and proteins, plant oils are renewable feedstocks for biorefineries in a future biobased economy. Biocatalysis already plays a role in the biorefinery, typically for carbohydrate hydrolysis and fermentation, but further contribution is foreseen. Analogously to carbohydrates, the first nonfood market of lipids is biofuel production, ${ }^{1}$ but a better use of plant oils would be the production of biobased chemicals with larger added value. ${ }^{2}$ In oil biorefinery applications, reactions often take place at the fatty-acid carboxyl group, e.g., for production of free fatty acids and their methyl esters, but interesting reactions can also be produced at the alkyl chains, e.g., by introducing reactive epoxides of application in organic synthesis. ${ }^{3,4}$
Industrial fatty-acid epoxidation is routinely carried out by the Prileschajew reaction ${ }^{5}$ where a strong mineral acid catalyzes the formation of percarboxylic acids that react with double bonds. Attempts to use milder and more efficient conditions include epoxidation catalyzed by acidic ionexchange resins and high-valence metals, ${ }^{6}$ and specially, the chemoenzymatic lipase $-\mathrm{H}_{2} \mathrm{O}_{2}$ reaction discovered by Novo Nordisk $^{7,8}$ (using e.g., Novozym 435 containing the immobi-

Received: July 20, 2020

Revised: October 23, 2020

Published: November 10, 2020

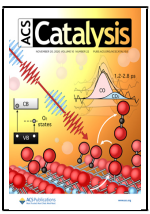


lized lipase CALB of Candida antarctica) that generates reactive fatty-acid peracids mediating oil epoxidation. Apart from some plant-seed peroxygenases (EC 1.11.2.3) used as crude preparations, ${ }^{9,10}$ direct epoxidation of (poly)unsaturated fatty acids can be catalyzed by eukaryotic and prokaryotic P450 monooxygenases (P450s), ${ }^{11}$ especially bacterial P450s due to easier availability. Among them, the well-known soluble Bacillus megaterium P450-BM3 ${ }^{12}$ (EC 1.6.2.4) integrates the flavoenzyme partner required by most $\mathrm{P} 450 \mathrm{~s}$ as a second protein domain, with the associated advantages. ${ }^{13}$ Nonetheless, drawbacks derived from the intracellular nature of P450s, including dependence on a $\mathrm{NAD}(\mathrm{P}) \mathrm{H}$ source, except for some wild/engineered $\mathrm{P} 450$ s being activated by $\mathrm{H}_{2} \mathrm{O}_{2}$ (peroxygenase activity), ${ }^{14}$ and low stability compared with extracellular enzymes, often hamper their implementation as enzymatic industrial biocatalysts.

In 2004, a secreted and stable unspecific peroxygenase (UPO; EC 1.11.2.1) only requiring $\mathrm{H}_{2} \mathrm{O}_{2}$ to be activated ${ }^{15,16}$ was discovered in liquid cultures of the fungus Agrocybe aegerita. ${ }^{17}$ Due to its ability to selectively oxygenate a variety of compounds, including unactivated hydrocarbons, UPOs have been termed "dream biocatalysts". ${ }^{18}$ A repertoire of regio- and stereoselective oxygenations are among the reactions of interest catalyzed by UPOs, such as hydroxylation of alkanes, ${ }^{19,20}$ fatty acids, ${ }^{21}$ flavonoids, ${ }^{22}$ steroids/secosteroids, ${ }^{23,24}$ stilbenoids, ${ }^{25}$ and flavors ${ }^{26,27}$ syntheses of drugs and drug metabolites, ${ }^{28-31}$ conversion of 2,5-hydroxymethylfurfural $^{32}$ chain-shortening of fatty acids ${ }^{33}$ and corticoids, ${ }^{34}$ and oxygenation (including epoxidation and rearomatization) of aromatic compounds, ${ }^{35}$ from benzene ${ }^{36}$ to complex pharmaceuticals, also including toluene, ${ }^{37}$ heterocycles, ${ }^{38}$ and polycyclic aromatic hydrocarbons. ${ }^{39}$ In fact, more than 350 different compounds have been shown to serve as UPO substrates. $^{16}$

Recently, epoxidation of unsaturated fatty-acids was incorporated to the repertoire of UPO reactions after its description for Marasmius rotula UPO (MroUPO) and a few other UPOs. ${ }^{40}$ Although epoxidation of small (sub)terminal alkenes had been reported for AaeUPO, ${ }^{41}$ this enzyme and the related UPO from Coprinopsis cinerea (CciUPO) did not epoxidize fatty acids unlike that reported for MroUPO. The epoxidation cycle of UPOs shares the activation by $\mathrm{H}_{2} \mathrm{O}_{2}$ (to compound-I, C-I) with the general peroxidase/peroxygenase catalytic cycle, but differs in the formation of a modified compound-II species (C-II*) facilitating epoxide cyclization, and in that, no $\mathrm{H}$-abstraction takes place in epoxidation (Figure 1). ${ }^{16}$

Epoxidation of fatty acids is of industrial interest for the production of PVC plasticizers and stabilizers, polyurethane polyols, lubricants, and biobased binder components. ${ }^{2,6,42}$ The potential of UPOs for these reactions is being further investigated by heterologous expression of upo genes, ${ }^{43}$ among several thousand putative UPOs identified in genomes, ${ }^{16}$ and protein engineering. ${ }^{44}$ Such studies are possible thanks to the reported Escherichia coli expression of MroUPO and then of other UPO genes. ${ }^{44,45}$

Here, we apply computational simulations to rationalize the enzyme and substrate specific patterns observed during the oxygenation of a number of unsaturated fatty acids by several UPOs. The aim is to unveil general rules governing the oxygenation patterns of unsaturated fatty acids by members of the UPO family, after a previous study ${ }^{44}$ where the possibility of modulating oleic acid epoxidation versus hydroxylation by

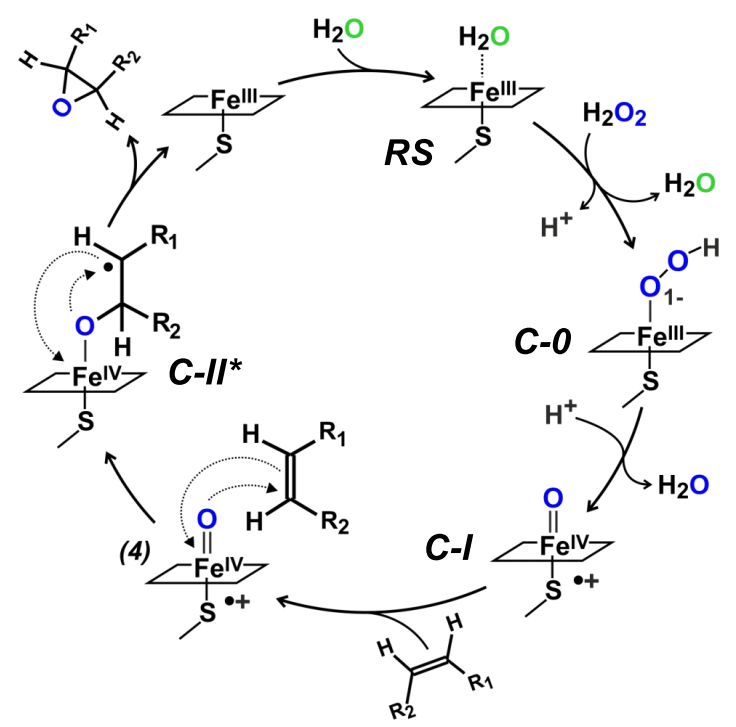

Figure 1. Proposed epoxidation cycle of UPO showing the activation of the resting state (RS) by $\mathrm{H}_{2} \mathrm{O}_{2}$, through hydroperoxo compound-0 $(\mathrm{C}-0)$, to form reactive $\mathrm{C}-\mathrm{I}$ able to epoxidize double bonds via a transient oxoferryl-substrate radical complex $\left(\mathrm{C}-\mathrm{II}^{*}\right)$.

MroUPO was described. In the present work, diffusion and local conformational sampling of the three main 18-carbon unsaturated fatty acids in vegetable oils (Figure S1A-C) are simulated on the molecular structures of AaeUPO, ${ }^{46}$ CciUPO, ${ }^{47}$ and MroUPO. ${ }^{44}$ The adaptive-PELE software, ${ }^{48}$ which incorporates a reward function improving sampling of nonvisited areas, is used in this first comprehensive comparison of the oxygenation of several unsaturated fatty acids by UPOs. Simultaneously, the products from the above reactions are experimentally analyzed by gas chromatography-mass spectrometry (GC-MS). Moreover, we take advantage of the possibility to engineer M. rotula UPO in E. coli (rMroUPO) ${ }^{44}$ to test the conclusions from the above combined analysis using a previously described site-directed variant. Finally, as a demonstration of the potential of the combined computational-experimental approach, synthesis of the 15,16-epoxide from $\alpha$-linolenic acid is shown at a small preparative scale with regio- and stereoselectivity.

\section{RESULTS AND DISCUSSION}

In a first part of the study, the structural determinants of regioselective oxygenation (epoxidation and stepwise hydroxylation yielding hydroxy, oxo, and carboxy derivatives) of different unsaturated fatty-acids by enzymes of the long-UPO and short-UPO subfamilies ${ }^{15}$ are unveiled by combined computational and experimental analyses. In a second part, the small-scale preparative production of 15,16 -epoxyoctadeca9,12-dienoic acid by UPO and subsequent product characterization by NMR, chiral HPLC, and other techniques was carried out revealing its regio- and enantioselective nature.

Unsaturated Fatty-Acid Oxygenation by Wild-Type UPOs. Experimental reactions with unsaturated fatty acids were first carried out employing two long UPOs, wild AaeUPO purified from fungal cultures ${ }^{49}$ and $\mathrm{rCciUPO}$ only known as a recombinant enzyme, ${ }^{50}$ and the short MroUPO obtained from E. coli (rMroUPO), ${ }^{44}$ for better comparison with variants produced in the same expression system. In these reactions, oleic, linoleic, and $\alpha$-linolenic acids (commonly found in plants) were reacted to attain complete conversion by 
Table 1. Substrate Conversion (\%) and Oxygenated Products (\% of Total) in UPO Reactions with Oleic (C18:1), Linoleic (C18:2), and $\alpha$-Linolenic (C18:3) Acids $^{a}$

\begin{tabular}{|c|c|c|c|c|c|c|c|c|c|c|c|c|}
\hline \multirow[b]{2}{*}{ substrate and enzyme } & \multirow[b]{2}{*}{ enzyme (nM) } & \multicolumn{10}{|c|}{ products $(\%)^{b}$} & \multirow[b]{2}{*}{ conversion (\%) } \\
\hline & & $15-\mathrm{E}$ & $12-\mathrm{E}$ & $9-\mathrm{E}$ & di-E & $\mathrm{OH}-\mathrm{moE}$ & OH-diE & $\mathrm{OH}$ & keto & di-COOH & other & \\
\hline \multicolumn{13}{|l|}{ - $\underline{\mathrm{C} 18: 1}$} \\
\hline AaeUPO & 100 & & & 0 & & 0 & 0 & 81 & 19 & 0 & 0 & 99 \\
\hline $\mathrm{rCciUPO}$ & 100 & & & 0 & & 0 & 0 & 96 & 4 & 0 & 0 & 99 \\
\hline rMroUPO & 200 & & & 40 & & 57 & 0 & 2 & 1 & 0 & 0 & $94(85)^{c}$ \\
\hline $\begin{array}{l}\mathrm{I} 153 \mathrm{~F} / \mathrm{S} 156 \mathrm{~F} \\
-\underline{\mathrm{C} 18: 2}\end{array}$ & 200 & & & 0 & & 0 & 0 & $16^{d}$ & 59 & 25 & 0 & $70(50)^{c}$ \\
\hline AaeUPO & 200 & & 0 & 0 & 0 & 0 & 0 & 35 & 45 & 0 & $20^{f}$ & 99 \\
\hline rCciUPO & 600 & & 0 & 0 & 0 & 0 & 0 & 24 & 57 & 0 & $19^{f}$ & 99 \\
\hline rMroUPO & 200 & & 1 & 0 & 25 & 50 & 24 & 0 & 0 & 0 & 0 & 98 \\
\hline $\begin{array}{l}\mathrm{I} 153 \mathrm{~F} / \mathrm{S} 156 \mathrm{~F} \\
\underline{-\mathrm{C} 18: 30}\end{array}$ & 600 & & 33 & 2 & 0 & 3 & 0 & $20^{e}$ & 38 & 4 & 0 & $71(30)^{c}$ \\
\hline AaeUPO & 100 & $>99$ & 0 & 0 & 0 & 0 & 0 & 0 & 0 & 0 & 0 & 99 \\
\hline rCciUPO & 100 & 1 & 0 & 0 & 0 & 93 & 0 & 0 & 0 & 0 & $6^{g}$ & 99 \\
\hline rMroUPO & 200 & 0 & 0 & 0 & 44 & 43 & 13 & 0 & 0 & 0 & 0 & 98 \\
\hline $\mathrm{I} 153 \mathrm{~F} / \mathrm{S} 156 \mathrm{~F}$ & 200 & 95 & 0 & 0 & 0 & 5 & 0 & 0 & 0 & 0 & 0 & 98 \\
\hline
\end{tabular}

${ }^{a}$ Reactions of $0.1 \mathrm{mM}$ fatty acids with $100-600 \mathrm{nM}$ enzyme at $30^{\circ} \mathrm{C}$ for $30 \mathrm{~min}$, analyzed by GC-MS (Figures S2-S4). ${ }^{b}$ Products include $15,16-$, 12,13-, and 9,10-epoxides (15-E, 12-E and 9-E, respectively), diepoxides (di-E), hydroxy-monoepoxides (OH-moE), hydroxy-diepoxides (OH$\mathrm{diE}$ ), and hydroxy $(\mathrm{OH})$, keto-, dicarboxylic (di-COOH), and other fatty-acid derivatives (formulae in Figures $\mathrm{S} 6-\mathrm{S} 8$ ). ${ }^{c} \mathrm{Conversions}$ with $100 \mathrm{nM}$ (C18:1) and $200 \mathrm{nM}(\mathrm{C} 18: 2)$ enzyme are shown in parentheses. ${ }^{d}$ Including $5 \% \omega$-OH derivative. ${ }^{e}$ Including $4 \% \omega$-OH derivative. ${ }^{f}$ Mainly hydroxy-keto derivatives. ${ }^{g}(\omega-1)$-Keto epoxide.

modifying the concentration of enzyme and/or $\mathrm{H}_{2} \mathrm{O}_{2}$ when required (although identical reaction conditions for the three enzymes were also tested). It is necessary to mention that the $\mathrm{H}_{2} \mathrm{O}_{2}$ dose in UPO reactions is always higher than stoichiometric due to the catalase-like activity of the enzyme. ${ }^{51}$ The reactions were extracted and analyzed by GC-MS (Figures S2-S4), and the different products (Figures S6S8) were identified from retention times and mass spectra ${ }^{40}$ and quantified (Table 1).

In agreement with previous studies using oleic acid as model-unsaturated fatty acid, ${ }^{21,40,44}$ epoxidation of this compound was observed with rMroUPO but not with AaeUPO or $\mathrm{rCciUPO}$, which mainly yielded the $(\omega-1)$ and $(\omega-2)$ hydroxy derivatives (Figure S2A-C). A second monounsaturated 18-carbon fatty acid, namely, cis-vaccenic (the $\Delta 11$ isomer of oleic acid rarely found in vegetable oils), was also tested to get further insights into the oxygenation ability of these enzymes. Very similar results were obtained with this substrate (Figures S5 and S9), with only rMroUPO forming the corresponding epoxide, although the ratio between the keto and hydroxy derivatives produced by AaeUPO and $\mathrm{rCciUPO}$ was higher than that observed in the oleic acid reactions (Table S1). Unexpectedly, we found that the two latter UPOs did epoxidize $\alpha$-linolenic acid with high conversion (Table 1). This is the first time that epoxidation of unsaturated fatty acids is reported for this firstly described and most exhaustively investigated ${ }^{15,16}$ UPO of $A$. aegerita.

The $A$. aegerita enzyme reveals itself as even more interesting because it epoxidizes $\alpha$-linolenic acid with strict regioselectivity forming only the 15,16-epoxide (Table 1 and Figure S4A). Conversely, $\mathrm{rCciUPO}$ forms hydroxyepoxides and $\mathrm{rMroUPO}$ a variety of epoxidized products, in consonance with previous studies. ${ }^{40,44}$ These results contrast not only with the oleic (and cis-vaccenic) acid oxygenation patterns by AaeUPO and rCciUPO described above but also with their action on linoleic acid that also yields subterminal hydroxy/keto (and not epoxide) derivatives. Moreover, as previously reported, ${ }^{40,44}$ a mixture of epoxy and hydroxy-epoxy products was generated in rMroUPO reactions with the three fatty acids, and a similar combination of 11,12-epoxide and its hydroxylated derivatives was found in the cis-vaccenic acid reactions (Figure S5C and Table S1).

Computational Simulations with Wild-Type UPOs. To understand the above regioselective oxygenation patterns by UPOs of the long (AaeUPO and CciUPO) and short (MroUPO) subfamilies, ${ }^{15}$ we analyzed the diffusion of the above three plant 18-carbon-unsaturated fatty acids (plus cisvaccenic acid for comparison) into the three enzymes and their conformation at the vicinity of the heme cofactor, using adaptive-PELE. $^{48}$ PELE software has been successfully applied to simulate the substrate migration and active-site access in different oxidoreductases. ${ }^{44,52,53}$ For these simulations, we used the available AaeUPO (PDB 2YP1) and MroUPO (5FUJ) crystal structures $^{16,46}$ and the CciUPO homology model ${ }^{47}$ after refinement with molecular dynamics (Figure S10).

The computational results consist of density and energetic plots of distances versus interaction energies, and representative snapshots from these plots (Figures S11-S26). A selection of the results obtained for the three main plant fatty acids is shown in Figure 2, which nicely summarizes the computational study performed. These results are presented as density plots of interaction energies versus distances between the oxo ligand in the simulated C-I (see Figure 1) of AaeUPO, CciUPO, and MroUPO and the main fatty-acid carbons being epoxidized $\left(\mathrm{C}_{10}, \mathrm{C}_{13}\right.$, and $\mathrm{C}_{16}$ in oleic acid $\Delta 9$, linoleic acid $\Delta 12$, and $\alpha$ linolenic acid $\Delta 15$, respectively, Figure 2, left) or subterminally $(\omega-1)$-hydroxylated $\left(\mathrm{C}_{17}\right.$ in the three fatty acids, Figure 2, right).

When the substrate double bonds attain reactive positions in the epoxidation plots (Figure 2, left), representative snapshots (from the best interaction-energy and shortest oxo- $\mathrm{C}$ distance areas) were selected and are shown in Figure 3 (the epoxidation panels in both figures are identified by a greenish background). These snapshots show the final fatty-acid 
Epoxidation plots
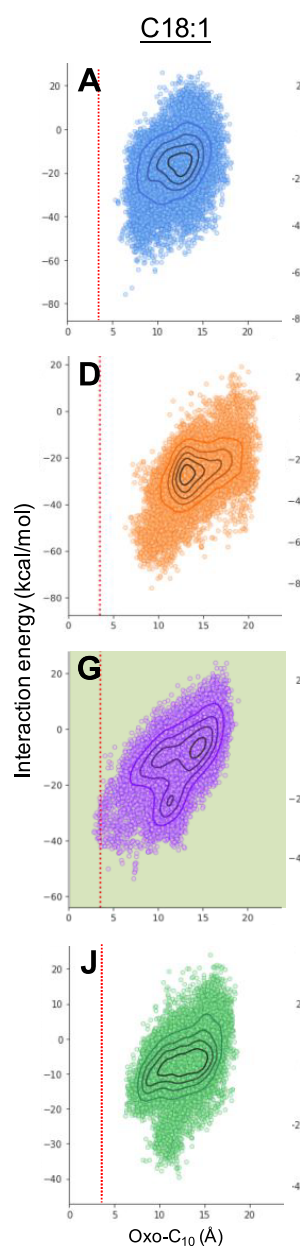

$\underline{\mathrm{C} 18: 2}$
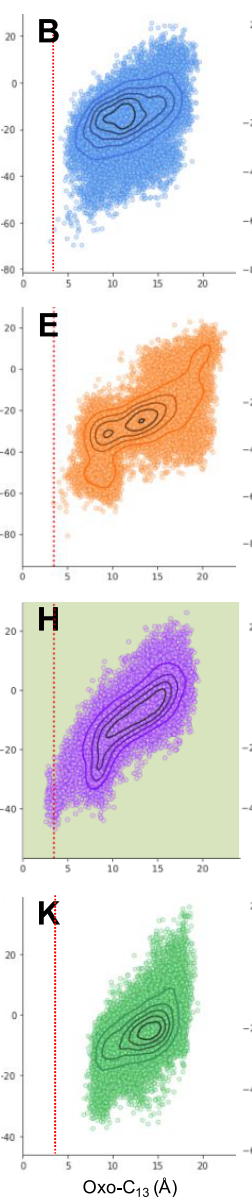

$\underline{\mathrm{C} 18: 3}$
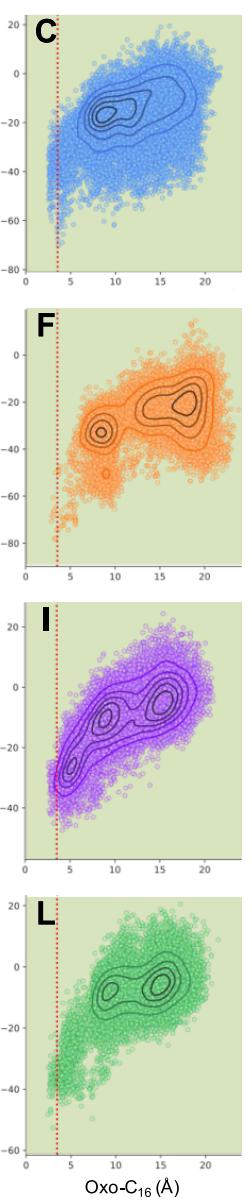

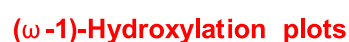

C18:1

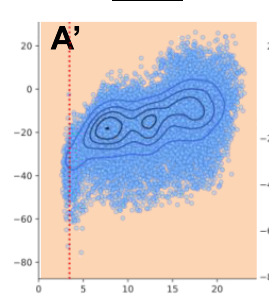

$\underline{\mathrm{C} 18: 2}$

$\underline{\mathrm{C} 18: 3}$
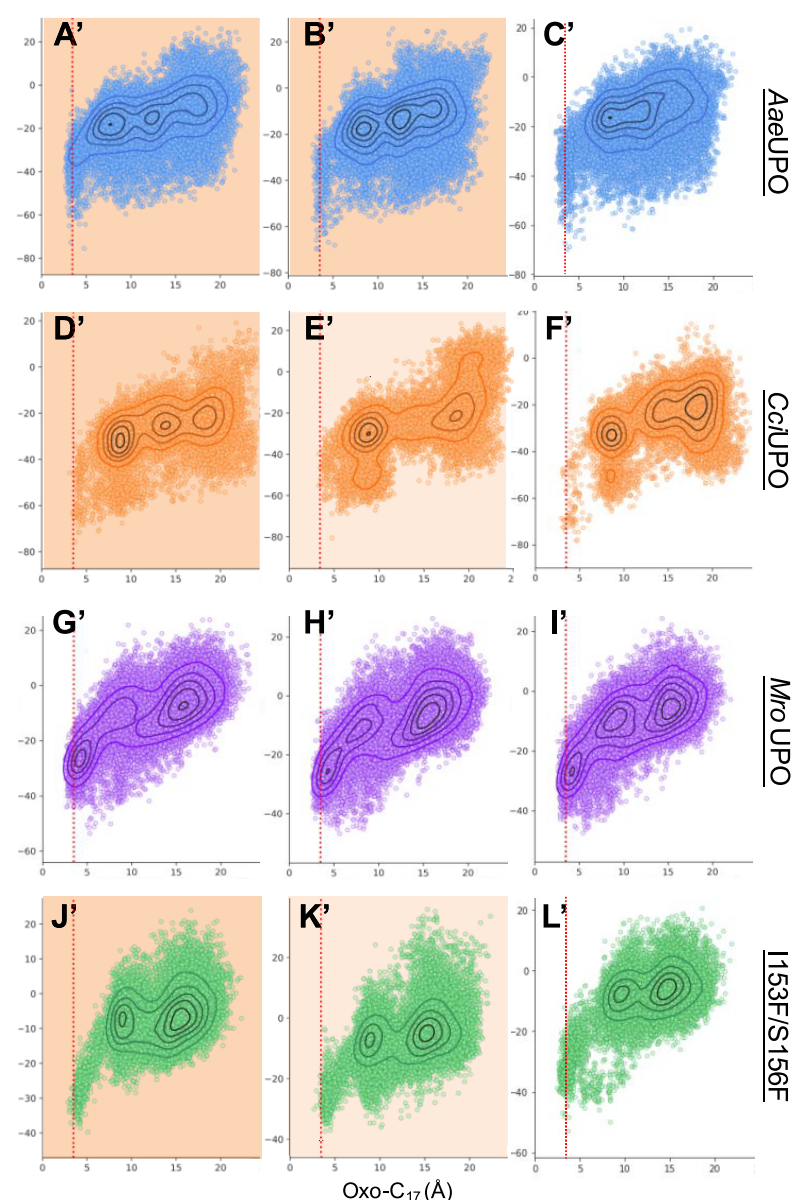

Figure 2. Substrate diffusion by PELE for studying epoxidation (left) and ( $\omega$-1) subterminal hydroxylation (right) by UPOs: Density plots of interaction energies vs distances between the oxo atom in simulated C-I of AaeUPO (blue), CciUPO (orange), MroUPO (purple), and its in silico mutated I153F/S156F variant (green); and (i) the olefinic $\mathrm{C}_{10}$ of oleic acid (C18:1), $\mathrm{C}_{13}$ of linoleic acid (C18:2), and $\mathrm{C}_{16}$ of $\alpha$-linolenic acid (C18:3) (left); or (ii) the $\mathrm{C}_{17}$ atom of the three fatty acids (right). The threshold of catalytically relevant $(<3.5 \AA)$ oxo-C distances is indicated by red lines, and selected snapshots from colored-background plots are shown in Figure 3 (see Figures S11-S22 for complete results).

conformation at the active site, the estimated distances from the $\mathrm{C}$-I oxo, and the nearest $\mathrm{H}$ atom at the $\mathrm{C}_{10} / \mathrm{C}_{13} / \mathrm{C}_{16}$ positions to be epoxidized. Although the oxo- $\mathrm{C}$ distances could be more meaningful from a mechanistic point of view (see Figure 1), the oxo-H distances (providing an almost identical analysis) are shown in Figure 3 for easier comparison with the hydroxylation reactions, mentioned below, and in agreement with previous studies. ${ }^{44}$ We should remark that these are not equilibrium simulations and that the density of points only reflects the difficulty in moving through (or reaching) the active site. The residence time at catalytic conformations is expected to be large enough for the reaction to take place based on the low binding energy values at the "catalytic point".

When the above epoxidation positions are not attained, reactive $(\omega-1)$-hydroxylation positions are generally observed in the density plots (Figure 2, right), and distances from the C$\mathrm{I}$ oxo and the nearest $\mathrm{H}$ atom at the $\mathrm{C}_{17}$ position are shown in Figure 3 (the hydroxylation panels are identified by a reddish background). The above preference is in agreement with the experimentally confirmed higher reactivity of olefinic positions (to be epoxidized) than of subterminal methylenes (to be hydroxylated) when located at equivalent distances of the C-I oxo due to the weaker $\mathrm{C}-\mathrm{C} \pi$-bond than $\mathrm{C}-\mathrm{H}$ bond. It is necessary to mention that $\mathrm{C}_{18}$ can also approach the C-I oxo (Figures S11-S22, bottom), but no reactivity (or a lower one) is expected since the fatty-acid substrate radical (Figure 1) is less stable at the terminal than at the subterminal position (the latter with greater hyperconjugation and/or resonance effects).

As shown in Figure 2 (left), in AaeUPO (blue plots), only the $\mathrm{C}_{16}$ atom of $\alpha$-linolenic acid $\Delta 15$ (panel C) attains relevant epoxidation distance $\left(<3.5 \AA\right.$ oxo-C), while the $C_{10}(\Delta 9)$ and $\mathrm{C}_{13}(\Delta 12)$ atoms of $\alpha$-linolenic, oleic, and linoleic acids always remain too far to be epoxidized. However, the $\mathrm{C}_{17}$ atom of the two latter acids (Figure 2, right) is close enough for hydroxylation reaction (panels $\mathrm{A}^{\prime}$ and $\mathrm{B}^{\prime}$, respectively). Similar results were obtained in the $C_{c i U P O}$ simulations although with slightly higher oxo-C distances (Figure 2, orange plots). The above results are illustrated in Figure 3 by representative substrate poses at the AaeUPO and CciUPO heme pockets. Those predict the epoxidation (greenish background) of $\alpha$ linolenic acid and the subterminal $\left(\mathrm{C}_{17}\right)$ hydroxylation (reddish background) of oleic and linoleic acids yielding $(\omega-1)$ hydroxy and keto derivatives, in agreement with the experimental results (Table 1). Subterminal hydroxylation was also predicted for reactions of the $\Delta 11$ isomer of oleic acid (cis- 


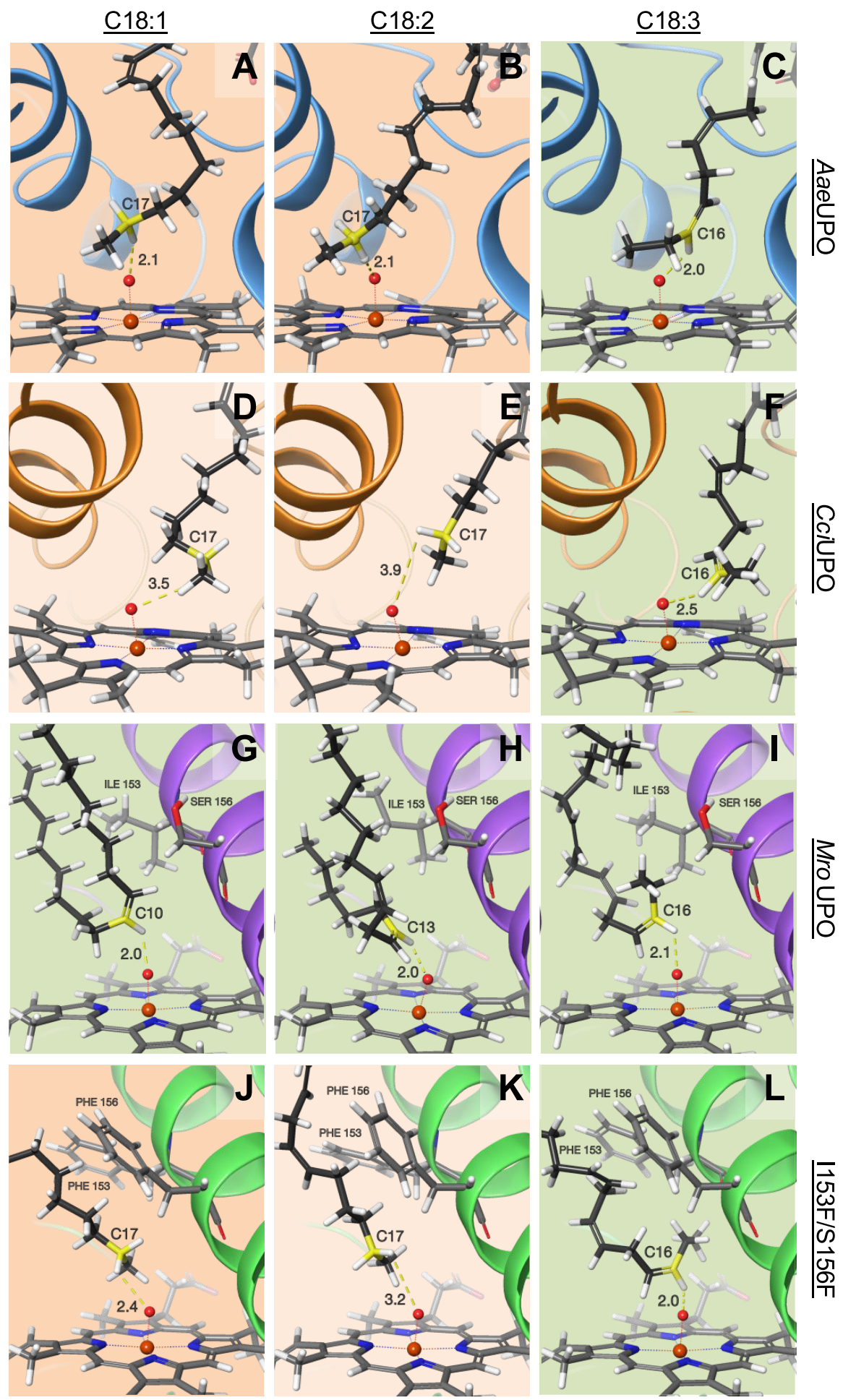

Figure 3. Selected snapshots from PELE plots (Figure 2) showing distances (in Å) from C-I oxo (upper red sphere) to olefinic (greenish background) or subterminal (reddish background) hydrogens of oleic (C18:1), linoleic (C18:2), and $\alpha$-linolenic (C18:3) acids diffused on AaeUPO, CciUPO, MroUPO, and its I153F/S156F variant (the lighter reddish background in (D), (E), and (K) reflects longer distances to fattyacid subterminal hydrogens). Catalytic distances to olefinic hydrogens in $(\mathrm{G})\left(\mathrm{H}-\mathrm{C}_{10}\right),(\mathrm{H})\left(\mathrm{H}-\mathrm{C}_{13}\right)$, and $(\mathrm{C}),(\mathrm{F}),(\mathrm{I})$, and $(\mathrm{L})\left(\mathrm{H}-\mathrm{C}_{16}\right)$ result in double-bond epoxidation (Table 1). Catalytic distances to methylenic hydrogens $\left(\mathrm{H}-\mathrm{C}_{17}\right)$ in $(\mathrm{A}),(\mathrm{B})$, and $(\mathrm{J})$ result in subterminal hydroxylation (Table 1). Fatty acids, heme -and Ile153, Ser156, Phe153 and Phe156 residues in (G)-(L) - are shown as sticks (see Figures S11-S22 for additional selected snapshots).

vaccenic acid) with the above two UPOs (Figures S23 and S24), which could be experimentally confirmed (Table S1).

In contrast to AaeUPO and $C c i \mathrm{UPO}$, unsaturations in the three 18-carbon plant fatty acids attain adequate epoxidation distances at the MroUPO active site (purple plots in Figure 2, left). The selected poses in Figure 3 show that the olefinic $\mathrm{C}_{10}$ $(\Delta 9)$ and $\mathrm{C}_{13}(\Delta 12)$ approach the $\mathrm{C}$-I oxo thanks to the bent conformation adopted by both oleic (panel G) and linoleic 
$(\mathrm{H})$ acids, whereas the $\mathrm{C}_{16}(\Delta 15)$ of $\alpha$-linolenic acid approaches it in a more extended configuration (I). Once again, results similar to those of oleic acid were obtained for its $\Delta 11$ isomer, in this case predicting epoxidation after attaining the MroUPO heme oxo in a bent conformation (Figure S25).

To get further insights into the formation of diepoxides in MroUPO reactions (Table 1), additional simulations with the main monoepoxides (at $\Delta 12$ and $\Delta 15$ of linoleic and $\alpha$ linolenic acids, respectively) could be done. However, the current computational results are consistent with the experimental results since both the linoleic acid $\mathrm{C}_{13} / \mathrm{C}_{10}$ positions and the $\alpha$-linolenic $\mathrm{C}_{16} / \mathrm{C}_{13}$ positions attain epoxidation distances in the fatty-acid plots (Figures S17 and S21, respectively).

Narrowed-Channel Variant of MroUPO. The ability of rMroUPO to epoxidize the above unsaturated fatty acids appears related to the possibility of accommodating them at catalytically relevant positions near the C-I oxo, owing to its already reported ${ }^{16}$ broad heme access channel (Figure 4C). The opposite would apply to AaeUPO and CciUPO due to their similarly constrained channels (Figure 4A,B).
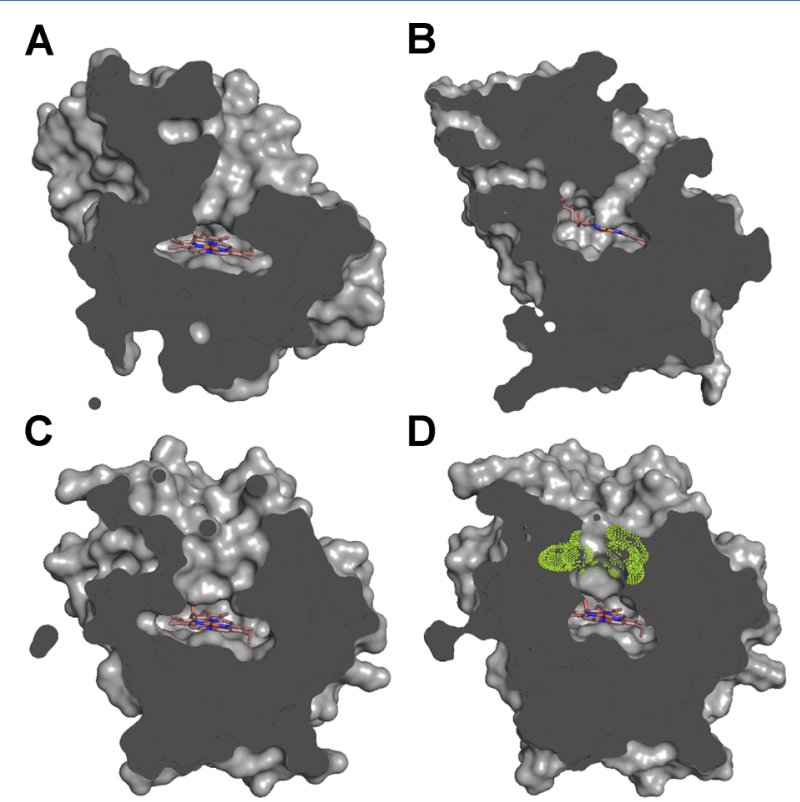

Figure 4. Sections of AaeUPO (A), CciUPO (B), MroUPO (C) and its in-silico mutated I153F/S156F variant (D) molecules showing the solvent access surface (gray) and the buried heme (sticks) with wide (in (C)) and narrow (in (A), (C), and (D)) access channels (the lemon zone in $(\mathrm{D})$ corresponds to the two introduced phenylalanine residues). From PDB entries 2YP1 (A) and 5FUJ (C), homology model (B), and in silico mutated variant (D).

To experimentally test the above hypothesis, we took advantage of the availability of the $1153 \mathrm{~F} / \mathrm{S} 156 \mathrm{~F}$ variant in which the heme channel of MroUPO has been experimentally narrowed by introducing two phenylalanine residues. ${ }^{44}$ It is noteworthy that AaeUPO possesses a number of aromatic residues lining the heme channel and its active site. Most of them are phenylalanine residues, which are thought to act as a clamp to accommodate the substrate over the heme cofactor. ${ }^{46}$ Particularly, the action of this variant on polyunsaturated fatty acids is studied here from both computational and experimental points of view for the first time. The narrowchannel (Figure 4D) in silico variant, generated from 5FUJ, provides epoxidation PELE plots (Figure 2J-L) similar to those obtained for AaeUPO and CciUPO (Figure $2 \mathrm{~A}-\mathrm{C}, \mathrm{D}-\mathrm{F}$, respectively) with only $\alpha$-linolenic acid approaching the I153F/S156F heme for double-bond epoxidation.

The epoxidation of $\alpha$-linolenic acid occurs at $\Delta 15$ with the $\mathrm{C}_{16}$ atom being able to reach the C-I oxo of the double variant due to its more terminal position. The $\alpha$-linolenic acid epoxidation pose for $1153 \mathrm{~F} / \mathrm{S} 156 \mathrm{~F}$ (Figure 3L) mimicked those of AaeUPO and $\mathrm{CciUPO}$ (Figure 3C,F, respectively), while a partially bent conformation of the substrate is predicted for the wild-type MroUPO (Figure 3I).

In addition, PELE predicts that when oleic acid enters the channel of the $\mathrm{I} 153 \mathrm{~F} / \mathrm{S} 156 \mathrm{~F}$ variant (adopting an extended conformation) the $\mathrm{C}_{17}$ (and not the $\mathrm{C}_{10}$ ) atom approaches the $\mathrm{C}-\mathrm{I}$ oxo (Figure $2 \mathrm{~J}$ and Figure S14) promoting subterminal hydroxylation (Figure 3J). A similar extended conformation is predicted for its $\Delta 11$ isomer (Figure S26), and the subterminal hydroxylation was experimentally confirmed (Table S1). Furthermore, linoleic acid would not attain the reactive oxo$\mathrm{C}_{13}$ distance for epoxidation by $\mathrm{I} 153 \mathrm{~F} / \mathrm{S} 156 \mathrm{~F}$ (Figure $2 \mathrm{~K}$ ) (and the partial epoxidation shown in Table 1 is due to the 3fold higher UPO dose).

The coincident computational predictions for AaeUPO and the $\mathrm{rMroUPO} \mathrm{I} 153 \mathrm{~F} / \mathrm{S} 156 \mathrm{~F}$ variant were confirmed by the highly regioselective $\Delta 15$ mono-epoxidation of $\alpha$-linolenic acid experimentally obtained with the double variant (Figure 5B), which reproduces the results of AaeUPO (Figure 5C) (while diepoxides were the main reaction products of wild-type rMroUPO, Figure 5A).

UPO Selective Synthesis at Small Preparative Scale. Given the interest of selective epoxidation, in a second part of the study, the above regio- and stereoselective epoxidation of $\alpha$-linolenic acid by two of the enzymes (Figure 5B,C) was transferred to a small-preparative scale. The reactions were extracted, and the epoxidized products were purified (by preparative TLC and column chromatography) with yields of 67 and $82 \%$, for the I153F/S156F variant of rMroUPO and wild AaeUPO, respectively. ${ }^{1} \mathrm{H}$ - and ${ }^{13} \mathrm{C}-\mathrm{NMR}$ spectra (Figure S27) confirmed the product identification as cis,cis-15,16epoxyoctadeca-9,12-dienoic acid. The triplet signal ( $\left.{ }^{1} \mathrm{H}-\mathrm{NMR}\right)$ corresponding to protons bonded at $\mathrm{C}_{18}$ shifted downfield from $0.98 \mathrm{ppm}$ (substrate) to $1.05 \mathrm{ppm}$ due to the negative induction caused by the oxygen atom of the oxirane ring. Chiral HPLC analyses revealed a clear predominance of one of the enantiomers that, based on literature, ${ }^{54}$ was identified as the $15(R), 16(S)$ isomer, with an enantiomeric excess (ee) of $83 \%$ in the $\mathrm{I} 153 \mathrm{~F} / \mathrm{S} 156 \mathrm{~F}$ reaction (Figure 6 ) and $80 \%$ in the AaeUPO reaction (Figure S28), in agreement with polarimetric measurements of $[\alpha]_{\mathrm{D}}^{27}-8^{\circ}(\mathrm{I} 153 \mathrm{FS} 156 \mathrm{~F})$ and $[\alpha]_{\mathrm{D}}^{27}-6^{\circ}$ (AaeUPO).

P450-BM3 has been used in stereoselective (and regioselective) syntheses of fatty acids epoxides ${ }^{55}$ and particularly that of the 15,16 -epoxide of $\alpha$-linolenic acid, ${ }^{54}$ but this is the first time that an UPO enzyme is used with this purpose. Apart from the higher selectivity that this UPO displays for the identified $15(R), 16(S)$ isomer (ee $83 \%$ vs $60 \%$ ), UPOs are known for their advantages over P450s in terms of stability and independence of reducing power. Similar enantioselectivities are found among the three-mixed monoepoxides produced by the broad-bean peroxygenase from $\alpha$-linolenic acid. In this case, most enantiomers at $\Delta 15$ and $\Delta 9$ correspond to the same $(R, S)$ isomer found here. ${ }^{10}$ 

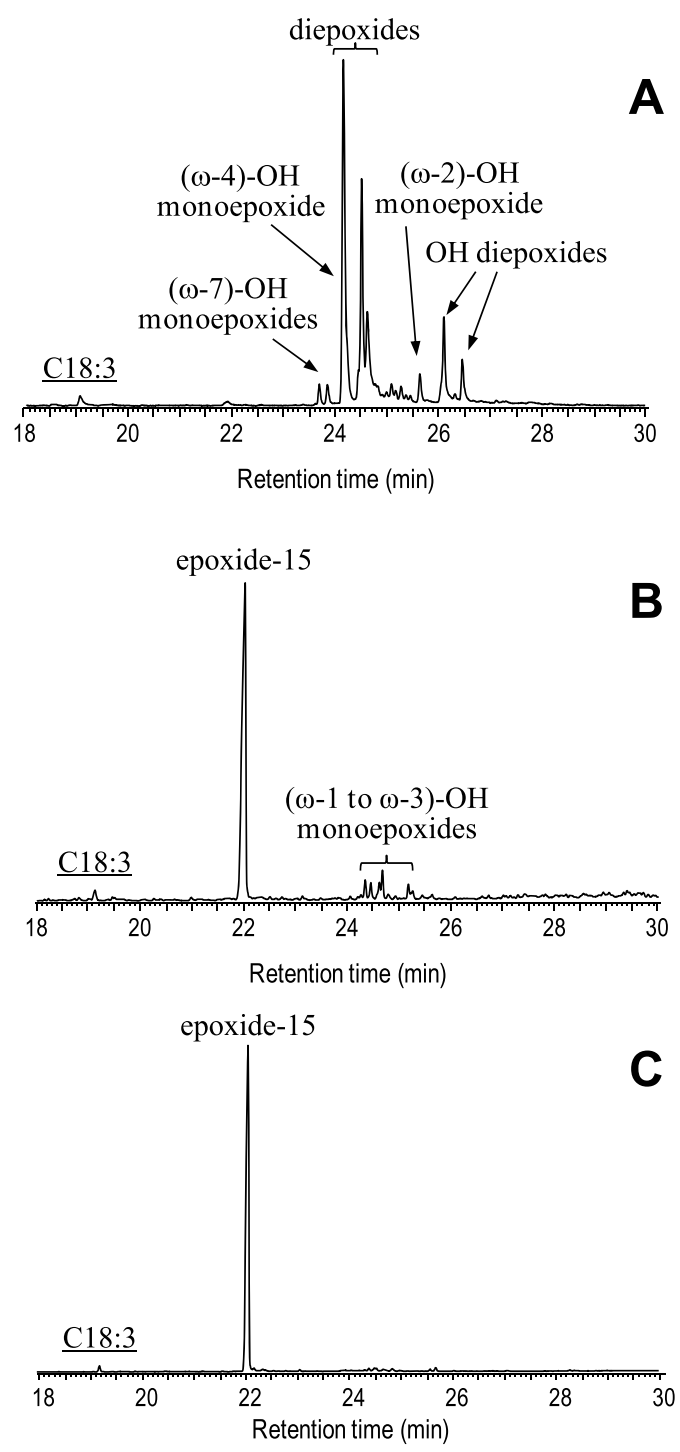

Figure 5. GC-MS analysis of $\alpha$-linolenic acid (C18:3, underlined) reactions with $\mathrm{rMroUPO}(\mathrm{A})$, its $\mathrm{I153 \textrm {F }} / \mathrm{S} 156 \mathrm{~F}$ variant (B), and AaeUPO (C) yielding 15,16-epoxyoctadeca-9,12-dienoic acid (epoxide-15) as the main product quantitation in the two latter cases. For reaction conditions and products, see Table 1.

Complete epoxidation of polyunsaturated fatty acids (in free and esterified forms) can be easily attained, e.g., using peracids generated by the lipase- $\mathrm{H}_{2} \mathrm{O}_{2}$ system, ${ }^{56}$ or exogenously added (as shown in Figure S29C for $\alpha$-linolenic acid treated with $m$ chloroperbenzoic acid, mCPBA). However, the above technologies are not selective enough to produce only monoepoxides since different double bonds are simultaneously epoxidized (Figure S29A,B). ${ }^{57}$ In fact, fully epoxidized fatty acids and vegetable oils are unsuitable even for some general applications (e.g., as paint diluents) due to their high viscosity (or solid nature under use conditions), ${ }^{58}$ while lower viscosity monoepoxides (due to retained double bonds) are advantageous. Given the lack of a suitable selective catalyst, the C15,C16 monoepoxide of $\alpha$-linolenic acid is not commercially available, despite being an interesting lipid molecule as explained below.

Regioisomers (or even enantioisomers) of $\alpha$-linolenic (and linoleic) acid monoepoxides have been specifically investigated for plant protection against pathogens by stimulating defense

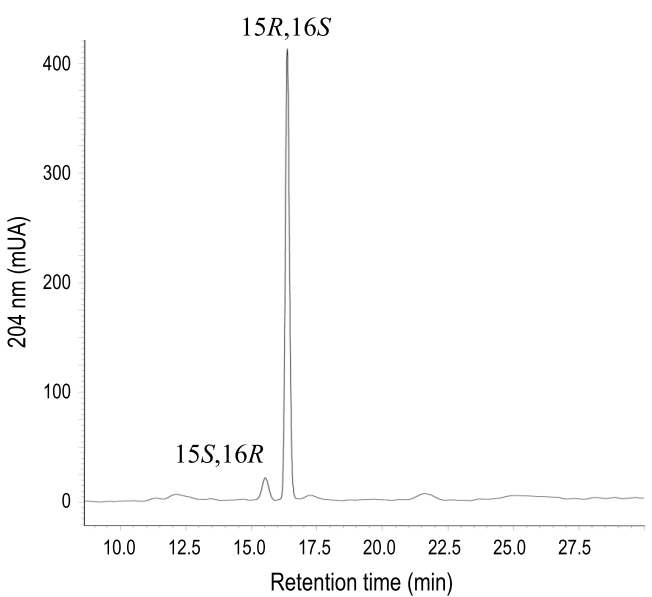

Figure 6. Chiral HPLC of epoxide-15 (cis,cis-15,16-epoxyoctadeca9,12-dienoic acid) from $\alpha$-linolenic acid reaction with the I153F/ S156F variant of MroUPO, resolving the main $15(R), 16(S)$ and minor $15(S), 16(R)$ enantiomers.

mechanisms. ${ }^{59-61}$ In a similar way, monoepoxides of these and other n-3 and n-6 (omega 3 and 6) fatty acids are involved in a variety of (patho)physiological responses in animals as lipid mediators, ${ }^{62}$ including antitumor activities. ${ }^{63,64}$ Interestingly, the linoleic $\Delta 12$ monoepoxide has been widely investigated both in plant seeds (as vernolic acid in oil industrial feedstock) ${ }^{65}$ and animal tissues (as citotoxic leukotoxin). ${ }^{66}$

The terminal epoxide of $\alpha$-linolenic acid (cis,cis-15,16epoxyoctadeca-9,12-dienoic acid) is only a minor component of some seed oils. ${ }^{67}$ This fact, together with the difficulties for its selective production using the current epoxidation technologies mentioned above, makes the enzymatic synthesis developed here as an attractive alternative to obtain this or other monoepoxides at the n-3 position of polyunsaturated fatty acids. In fact, the $\alpha$-linolenic acid epoxidation method described has a three-fold interest since it, as follows: (i) does not generate di- or triepoxides; (ii) only produces one of the three possible monoepoxides, i.e., the C15,C16 epoxide involved in (patho)physiological responses; and (iii) performs the epoxidation reaction in an enantioselective way, of additional importance considering the growing evidence of enantiospecific biological reactions.

Finally, it is interesting to mention that, as previously advanced, ${ }^{44}$ the engineered $\mathrm{I153F} / \mathrm{S} 156 \mathrm{~F}$ variant of $\mathrm{rMroUPO}$ is also the sole UPO reported to date catalyzing terminal oxygenation of oleic acid (and of linoleic acid as well) forming up to $25 \%$ octadec-9-enedioic acid (Table 1 and Figure S2D) by stepwise peroxygenation. Only $\omega-1$ and $\omega-2$ oxygenation of oleic acid is produced by AaeUPO (Figure S2A), a fact probably related to shorter oxo- $\mathrm{C}_{18}$ (with respect to oxo- $\mathrm{C}_{17}$ ) distances in the double variant compared with the former enzyme (Figures S14 and S11, respectively). Terminal oxygenation is a highly desired reaction for production of fatty-acid polyesters that has been reported to different extents

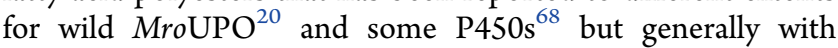
saturated fatty acids. Therefore, the rMroUPO I153F/S156F variant is also unique in generating unsaturated dicarboxylic fatty acids, compared with known fatty-acid oxygenating enzymes. This terminal oxygenation of oleic acid is reminiscent of the $\omega$-hydroxylation selectivity of plant CYP94A2 on saturated fatty acids, which also involves an active-site phenylalanine. ${ }^{6}$ However, this and other P450 regioselectiv- 
ities depend on the fatty-acid length, ${ }^{70}$ while regioselectivity in UPOs relies on other structural determinants and a less strict length dependence exists in UPO reactions. ${ }^{21}$

\section{CONCLUSIONS}

The observed enzyme and substrate specificities in epoxidation (and hydroxylation) of unsaturated 18-carbon fatty acids by available members of the long-UPO and short-UPO subfamilies were rationalized by computational simulation and supported by site-directed mutagenesis. We conclude that both enzyme and substrate structural determinants govern the existing selectivity in epoxidation of unsaturated fatty acids by UPOs. Such determinants, related to the heme pocket architecture and substrate double bond distribution, need to be taken into account for developing both improved UPOs and new biocatalytic processes using these enzymes.

One of the most remarkable experimental findings was the fatty-acid epoxidation ability of the first-described and bestknown UPO of $A$. aegerita. Such activity, which could not be demonstrated in previous studies using oleic acid as a model substrate, was brought to light here using $\alpha$-linolenic acid. Computational simulations of the above reactions shed light on the above discrepancy, revealing that a narrow heme-access channel in AaeUPO prevents access of the oleic acid double bond to the reactive C-I but perfectly accommodates $\alpha$ linolenic acid for the regio- and stereoselective epoxidation of its more terminal double bond. This explanation was experimentally confirmed by narrowing the heme channel of MroUPO in the I153F/S156F variant, which showed the same regioselective epoxidation pattern observed with AaeUPO.

Interestingly, the combined computational and experimental study finally resulted in successful preparative-scale epoxidation of $\alpha$-linolenic acid with ad hoc peroxygenases. In this way, the reaction regioselectivity was confirmed by NMR and, more importantly, its enantioselectivity could be demonstrated by chiral HPLC and other methods, yielding cis,cis-15(R),16(S)octadeca-9,12-dienoic acid $(80-83 \% e e)$. This is a noncommercially available compound of interest for (patho)physiological responses in both plants and animals. Given the substrate diffusion mechanism revealed by computational simulations, the new enzymatic conversion could be extended to other polyunsaturated fatty acids whose n-3 epoxides are of interest.

It is worth mentioning that, in contrast to the high number of studies on P450 engineering, ${ }^{71,72}$ only a few publications on UPO directed evolution ${ }^{30,73}$ or rational design ${ }^{43,44}$ have been produced to date. Additional studies combining experimental and computational approaches may pave the way to ad-hoc redesigning promising UPO biocatalysts ${ }^{16,18}$ in further syntheses of oxygenated compounds of interest including biobased chemicals. The increasing interest on UPOs as synthetic biocatalysts is demonstrated by the high number of review articles on these enzymes very recently published. ${ }^{16,31,74-76}$

\section{MATERIAL AND METHODS}

Molecular Models. The entrance pathways of four fatty acids (oleic, linoleic, $\alpha$-linolenic, and cis-vaccenic acids, Figure S1) were computationally studied in AaeUPO, MroUPO, and CciUPO. The MroUPO model was obtained from a crystallographic structure, 5FUJ. Although it has a dimeric nature, only chain-A was considered for two reasons: to be consistent with already published results, ${ }^{44}$ and because negligible interaction is expected between the ligand and the C-terminal loop of chain B. In silico mutated residues in the $1153 \mathrm{~F} / \mathrm{S} 156 \mathrm{~F}$ variant were relaxed by side-chain prediction over them and their closest residues with Prime. ${ }^{77}$ The model for AaeUPO was also obtained from a crystallographic structure, 2YP1, and only chain A was included as it is a fully functional monomer.

The structure of $\mathrm{CciUPO}$ was obtained from its sequence through homology modeling. ${ }^{47}$ The resulting model from BLAST $^{78}$ and Structure Prediction Wizard from Schrödinger ${ }^{79}$ was resolved with an identity of $60 \%$. However, a loop present at the entrance channel had no known crystallographic matches and could present different conformations (Figure S10). To determine the most stable conformation of this loop, a molecular dynamic simulation of $400 \mathrm{~ns}$ was performed over the homology model. The most stabilized pose was taken as the initial one by PELE.

In all cases, structural water molecules (with $2+$ hydrogen bonds with the protein) were included in the models, and systems were protonated at $\mathrm{pH} 5.5$ using Protein Preparation Wizard from Schrödinger. ${ }^{79}$ The heme group was modeled as the two-electron-oxidized compound C-I, and its atomic parameters were obtained with a quantum mechanics/ molecular mechanics minimization using QSite. ${ }^{80}$ The rest of the parameters were obtained from the OPLS2005 force field. The force-field parameters of heme C-I in UPO were previously reported. $^{43}$

Adaptive PELE Simulations. PELE is a heuristic Monte Carlo (MC) method combining an initial random perturbation where the ligand is translated/rotated and the backbone is displaced using normal modes, with a relaxation second phase including protein structure prediction algorithms: side chain prediction and minimization. ${ }^{81}$ In this study we used its enhanced-sampling version, adaptive-PELE. ${ }^{48}$

A total of 60 epochs of 12 PELE steps each was conducted in 128 processors, at the MareNostrum supercomputer (www. bsc.es/marenostrum). After each epoch, trajectories were clustered and new explorations were spawned on the most poorly explored regions to increase sampling efficiency. The initial position for the fatty acid was obtained from a Glide ${ }^{77}$ docking on the protein surface (avoiding the active site). At each PELE MC step, the substrate was perturbed by applying a translation vector modulus comprised between 0.5 and $1.25 \AA$ and a rotation angle between $2 \pi / 5$ and $\pi / 10$ radians. The backbone was perturbed every $5 \mathrm{MC}$ steps, and all side chains within $4 \AA$ from the substrate were sampled every two MC steps. Protein and substrate were described at the OPLS2005 force field level of theory. Enzyme-substrate interaction energies were derived as $\mathrm{Eab}-(\mathrm{Ea}+\mathrm{Eb})$ where $\mathrm{Eab}$ is the total energy of the complex and $\mathrm{Ea}$ and $\mathrm{Eb}$ the energies of the enzyme and the substrate, respectively, at the OPLS2005 level of theory.

Enzyme Production. AaeUPO (isoform II, $46 \mathrm{kDa}$ ) is a wild (i.e., nonrecombinant) enzyme from cultures of $A$. aegerita TM-A1 in a soybean-peptone liquid medium, which was purified as described elsewhere. ${ }^{49} \mathrm{rCciUPO}(44 \mathrm{kDa})$ was provided by Novozymes A/S. It corresponds to the protein model 7249 from the genome of $C$. cinerea sequenced at the US Department of Energy JGI (http://genome.jgi.doe.gov/ Copci1), which was expressed by Novozymes in Aspergillus oryzae (patent $\mathrm{WO} / 2008 / 119780$ ) and used in several studies. $^{23,24,26,50}$ The above enzymes were purified by fast protein liquid chromatography using a combination of size- 
exclusion and ion-exchange on different anion and cation exchangers. Purification was confirmed by sodium dodecylsulfate-polyacrylamide gel electrophoresis and UV-vis spectroscopy following the characteristic heme-maximum around 420 $\mathrm{nm}$ (Soret band of resting-state heme-thiolate proteins). Enzyme concentration was estimated according to the characteristic UV-vis band of the reduced-UPO adduct with carbon monoxide. ${ }^{82}$

Wild-type recombinant (native) rMroUPO was expressed as a soluble cytosolic protein in E. coli according to patent under application number EP 18382514 and subsequent publication. ${ }^{44}$ With this purpose, the MroUPO protein sequence available from NCBI (as 5FUJ_A) and RCSB-PDB (as SFUJ_1) was adapted for expression in E. coli by codon usage optimization using the Optimizer software, ${ }^{83}$ cloned into the pET23a plasmid under the control of the T7lac promoter and transformed into E. coli BL21 cells, which were grown in the ZYM-5052 medium ${ }^{84}$ at $16{ }^{\circ} \mathrm{C}$ for 4 days. Cells were harvested by centrifugation $\left(11,000 \mathrm{~g}, 4^{\circ} \mathrm{C}\right.$, and $\left.5 \mathrm{~min}\right)$, treated with lysozyme, sonicated, and debris removed by ultracentrifugation $\left(140,000 g, 4{ }^{\circ} \mathrm{C}\right.$, and $\left.90 \mathrm{~min}\right)$. An electrophoretically homogeneous enzyme was obtained after three chromatographic steps (two anionic at $\mathrm{pH} 7.0$ and one final cationic at $\mathrm{pH} 4.0$ ). Proper folding and binding of the cofactor and enzyme concentration were assessed from the UV-vis spectrum and the formation of the carbon monoxide adduct, respectively, as mentioned above.

The narrow-channel rMroUPO variant (I153F/S156F) was prepared using the Expand Long Template PCR kit from Roche (Basel, Switzerland) for site-directed mutagenesis. PCR reactions were run using the 5'-CCGATTTAACTGCGACTTTCCGCTCTTTCGAATCTGCG-3' DNA oligo harboring the desired mismatches (underlined nucleotides in bold triplets) and its reverse complementary counterpart, as previously described. ${ }^{44}$ The mutated upo gene was expressed in E. coli as described above for the native rMroUPO.

Experimental Reactions. Oleic (cis-octadec-9-enoic) acid, linoleic (cis,cis-octadeca-9,12-dienoic) acid, and $\alpha$-linolenic (cis,cis,cis-octadeca-9,12,15-trienoic) acid were obtained from Sigma-Aldrich, and cis-vaccenic acid (cis-octadec-11-enoic acid) was obtained from Merk. $( \pm)$ cis-9,10-Epoxyoctadecanoic acid and $( \pm)$ 9(10)-EpOME (cis-9,10-epoxidized linoleic acid) from Santa Cruz Biotechnology, ( \pm ) 12(13)-EpOME (12,13-cis-epoxidized linoleic acid) from Cayman, and $( \pm)$ 9,10-12,13-diepoxyoctadecanoic acid from Larodan were used as epoxide standards.

Chemically epoxidized $\alpha$-linolenic acid was prepared using $1.3,2.7$, and 4.5 equiv of $m \mathrm{CPBA}$ aiming to obtain preparations enriched in mono-, di-, and triepoxides respectively. With this purpose, $m \mathrm{CPBA}$ was added to a solution of $\alpha$-linolenic acid $(0.036 \mathrm{mmol})$ in $\mathrm{CHCl}_{3}(1 \mathrm{~mL})$ at room temperature for $30 \mathrm{~min}$. The reactions were quenched with saturated $\mathrm{NaHCO}_{3}$, and then the organic layers were washed with water and dried with $\mathrm{MgSO}_{4}$. An aliquot from each reaction was dried under $\mathrm{N}_{2}$ and derivatized with $\mathrm{N}, \mathrm{O}$ bis(trimethylsilyl)trifluoroacetamide (BSTFA, Supelco) to obtain the TMS derivatives that were analyzed by GC-MS.

Fatty acid $(0.1 \mathrm{mM})$ reactions with AaeUPO, rCciUPO, rMroUPO, and its mutated I153F/S156F variant (100-600 $\mathrm{nM}$ ) were performed in $50 \mathrm{mM}$ phosphate, $\mathrm{pH} 7.0$ (except for the native and mutated $\mathrm{rMroUPO}$ reactions that were at $\mathrm{pH}$ 5.5 ) at $30{ }^{\circ} \mathrm{C}$ for $30 \mathrm{~min}$, in the presence of 2.5-5 $\mathrm{mM} \mathrm{H}_{2} \mathrm{O}_{2}$. The substrates were dissolved in acetone and added to a final acetone concentration of $20 \%(\mathrm{v} / \mathrm{v})$. Products were recovered by extraction with methyl tert-butyl ether, dried under $\mathrm{N}_{2}$, and treated with BSTFA for GC-MS, as described below.

Chromatographic analyses of the reaction products were performed with a Shimadzu GC-MS QP2010 Ultra equipment, using a fused-silica DB-5HT capillary column (30 m $\times$ $0.25 \mathrm{~mm}$ internal diameter, $0.1 \mu \mathrm{m}$ film thickness) from $\mathrm{J} \& \mathrm{~W}$ Scientific. The oven was heated from $120{ }^{\circ} \mathrm{C}(1 \mathrm{~min})$ to 300 ${ }^{\circ} \mathrm{C}(15 \mathrm{~min})$ at $5{ }^{\circ} \mathrm{C} \cdot \mathrm{min}^{-1}$. The injection was performed at $300{ }^{\circ} \mathrm{C}$, and the transfer line was kept at $300{ }^{\circ} \mathrm{C}$. Compounds were identified using authentic standards, by mass fragmentography, and comparing their mass spectra with those of the Wiley and NIST libraries. Quantifications were obtained from total-ion peak areas, using external standard curves and molar response factors of the same (when commercially available) or similar compounds.

Controls without enzyme were included in all the fatty-acid reactions performed but no oxygenation products were detected in any of them, and the same happened when the UPO reactions were performed both using thermally inactivated UPO and in the absence of $\mathrm{H}_{2} \mathrm{O}_{2}$. Additional controls with epoxide standards (and different conditions) confirmed that no epoxide hydrolysis took place under the experimental conditions used.

Scaling-up $\alpha$-Linolenic Acid Epoxidation. $\alpha$-Linolenic acid was epoxidized with the I153F/S156F variant of $\mathrm{rMroUPO}$ and the wild AaeUPO in several $350 \mathrm{~mL}$ reactions under the same conditions described above. After $30 \mathrm{~min}$, the reaction was extracted, and the 15,16-epoxide was purified by preparative TLC (using 20:1 $\mathrm{MeOH}_{-} \mathrm{CHCl}_{3}$, as eluent) or column chromatography (using $\mathrm{MeOH}-\mathrm{CHCl}_{3} 40: 1 \rightarrow$ 10:1, as eluent), the yields were gravimetrically estimated.

The chemical identity of the cis,cis-15,16-epoxyoctadeca9,12-dienoic acid obtained was confirmed by NMR in a spectrometer Bruker Avance NEO $500 \mathrm{MHz} .{ }^{1} \mathrm{H}-\mathrm{NMR}(500$ $\mathrm{MHz}, \mathrm{CDCl}_{3}$ ): $\delta$ 5.53-5.30 (m, 4H, H-9, H-10, H-12, H-13), 2.96 and $2.91\left(2 \mathrm{dt}, 1 \mathrm{H}\right.$ each, $J_{15,16}=4.2 \mathrm{~Hz}, J=6.4 \mathrm{~Hz}, \mathrm{H}-15$, $\mathrm{H}-16), 2.80$ (t, $2 \mathrm{H}, J=7.0 \mathrm{~Hz}, \mathrm{H}-11), 2.41\left(2 \mathrm{dt}, 1 \mathrm{H}, J_{14 \mathrm{a}, 14 \mathrm{~b}}=\right.$ $15.2 \mathrm{~Hz}, J=6.4 \mathrm{~Hz}, \mathrm{H}-14 \mathrm{a}), 2.34$ (t, $2 \mathrm{H}, J=7.3 \mathrm{~Hz}, \mathrm{H}-2), 2.22$ $\left(2 \mathrm{dt}, 1 \mathrm{H}, J_{14 \mathrm{~b}, 14 \mathrm{a}}=15.2 \mathrm{~Hz}, \mathrm{H}-14 \mathrm{~b}\right), 2.04(\mathrm{~m}, 2 \mathrm{H}, \mathrm{H}-8), 1.62$ (m, 2H, H-3), 1.54 (m, 2H, H-17), 1.36-1.28 (m, 8H, H-4, H$5, \mathrm{H}-6, \mathrm{H}-7)$, and $1.05(\mathrm{t}, 3 \mathrm{H}, J=7.5 \mathrm{~Hz}, \mathrm{H}-18) \mathrm{ppm} .{ }^{13} \mathrm{C}-$ NMR (125 MHz, $\left.\mathrm{CDCl}_{3}\right): \delta 179.4(\mathrm{COOH}), 130.9,130.7$, 127.4 and 124.3 (C-9, C-10, C-12 and C-13), 58.6 and 56.8 (C-15 and C-16), 29.6, 29.2, 29.1, 29.0, 27.3, 26.3, 26.0, 24.8 and 21.2 (C-2, C-3, C-4, C-5, C-6, C-7, C-8, C-11, C-14 and $\mathrm{C}-17$ ), and 10.7 (C-18) ppm.

The reaction stereoselectivity was analyzed by chiral HPLC with a Thermo Scientific Ultimate 3000 UHPLC equipment, using a Daicel OJ-H $(4.6 \times 250 \mathrm{~mm})$ column. The mobile phase, hexane-iProOH (98.5:1.5, degassed with a $\mathrm{N}_{2}$ stream for $30 \mathrm{~min}$ ), was eluted at a flow rate of $0.3 \mathrm{~mL} \cdot \mathrm{min}^{-1}$. Optical rotation was measured on a polarimeter Jasco P-2000 using dichloromethane as a solvent.

\section{ASSOCIATED CONTENT}

\section{s) Supporting Information}

The Supporting Information is available free of charge at https://pubs.acs.org/doi/10.1021/acscatal.0c03165.

Comparison of cis-vaccenic acid and oleic acid conversion and products (Table S1); formulae of the four fatty-acid substrates (Figure S1); GC-MS analyses 
of oleic acid (Figure S2), linoleic acid (Figure S3), $\alpha$ linolenic acid (Figure S4), and cis-vaccenic acid (Figure S5) reactions with wild-type UPOs and mutated variant; formulae of oleic acid (Figure S6), linoleic acid (Figure S7), $\alpha$-linolenic acid (Figure S8), and cis-vaccenic acid (Figure S9) reaction products; molecular model of CciUPO (Figure S10); results of PELE diffusion of oleic acid (Figures S11-S14), linoleic acid (Figures S15S18), $\alpha$-linolenic acid (Figures S19-S22), and cisvaccenic acid (Figures S23-S26) on the wild-type UPOs and the rMroUPO variant; ${ }^{1} \mathrm{H}$ - and ${ }^{13} \mathrm{C}-\mathrm{NMR}$ spectra of enzymatic epoxide-15 from $\alpha$-linolenic acid (Figure S27); Chiral HPLC of enzymatic epoxide-15 from $\alpha$-linolenic acid (Figure S28); GC-MS analysis of linolenic acid reaction with mCPBA (Figure S29); and supporting references (PDF)

\section{AUTHOR INFORMATION}

\section{Corresponding Authors}

Victor Guallar - Barcelona Supercomputing Center, Barcelona E-08034, Spain; ICREA, Barcelona E-08010, Spain; ○ orcid.org/0000-0002-4580-1114; Email: victor.guallar@ bsc.es

Ana Gutiérrez - Instituto de Recursos Naturales y Agrobiología de Sevilla, CSIC, Seville E-41012, Spain; ○ orcid.org/0000-0002-8823-9029; Email: anagu@ irnase.csic.es

Angel T. Martínez - Centro de Investigaciones Biológicas Margarita Salas, CSIC, Madrid E-28040, Spain; ○ orcid.org/0000-0002-1584-2863; Email: ATMartinez@ cib.csic.es

\section{Authors}

Martí Municoy - Barcelona Supercomputing Center, Barcelona E-08034, Spain

Alejandro González-Benjumea - Instituto de Recursos Naturales y Agrobiología de Sevilla, CSIC, Seville E-41012, Spain; (1) orcid.org/0000-0003-2857-9491

Juan Carro - Centro de Investigaciones Biológicas Margarita Salas, CSIC, Madrid E-28040, Spain

Carmen Aranda - Instituto de Recursos Naturales y Agrobiología de Sevilla, CSIC, Seville E-41012, Spain

Dolores Linde - Centro de Investigaciones Biológicas Margarita Salas, CSIC, Madrid E-28040, Spain

Chantal Renau-Mínguez - Centro de Investigaciones Biológicas Margarita Salas, CSIC, Madrid E-28040, Spain

René Ullrich - Technische Universität Dresden, International Institute Zittau, Zittau D-02763, Germany

Martin Hofrichter - Technische Universität Dresden, International Institute Zittau, Zittau D-02763, Germany

Complete contact information is available at:

https://pubs.acs.org/10.1021/acscatal.0c03165

\section{Author Contributions}

${ }^{+}$M.M., A.G-.B., and J.C. equally contributed to the work.

Notes

The authors declare no competing financial interest.

Data underlying this article are available in the article and its online Supporting Information. Any additional information on the computational simulations, the wild and recombinant enzymes and their heterologous expression systems, the preparative epoxidation and product analysis methods, and other aspects of the article can be obtained on request to the corresponding authors.

\section{ACKNOWLEDGMENTS}

This work has received funding from the Bio Based Industries Joint Undertaking under the European Union's Horizon 2020 research and innovation programme under Grant Agreement No 792063 ("Development and pilot production of sustainable binder systems for wood based panels”, https://susbind.eu), the CTQ2016-79138-R and BIO2017-86559-R projects of Spanish MINECO, the Secretaria d'Universitats i Recerca of Generalitat de Catalunya, and the European Social Fund (ESF2019-FI-B-00154). The authors thank Novozymes A/S for supplying $\mathrm{rCciUPO}$. MM acknowledges a Catalan Government doctoral grant.

\section{REFERENCES}

(1) Huber, G. W.; Iborra, S.; Corma, A. Synthesis of transportation fuels from biomass: Chemistry, catalysts, and engineering. Chem. Rev. 2006, 106, 4044-4098.

(2) Corma, A.; Iborra, S.; Velty, A. Chemical routes for the transformation of biomass into chemicals. Chem. Rev. 2007, 107, 2411-2502.

(3) Yudin, A. K.; Aziridines and epoxides in organic synthesis; Wiley: New Jersey, 292 pp, 2006.

(4) Biermann, U.; Friedt, W.; Lang, S.; Lühs, W.; Machmüller, G.; Metzger, U. O.; Klaas, M. R. G.; Schäfer, H. J.; Schneider, M. P. New syntheses with oils and fats as renewable raw materials for the chemical industry; In Biorefineries-Industrial processes and products; Kamm, B.; Gruber, P. R.; Kamm, M., Eds.; Wiley-VCH Verlag GmbH: 2005, pp. 253-289, DOI: 10.1002/9783527619849.ch25.

(5) Prileschajew, N. Oxydation ungesättigter Verbindungen mittels organischer Superoxyde. Ber. Dtsch. Chem. Ges. 1909, 42, 4811-4815.

(6) Tan, S. G.; Chow, W. S. Biobased epoxidized vegetable oils and its greener epoxy blends: A review. Polym.-Plast. Technol. Eng. 2010, 49, 1581-1590.

(7) Björkling, F.; Frykman, H.; Godtfredsen, S. E.; Kirk, O. Lipase catalyzed synthesis of peroxycarboxylic acids and lipase mediated oxidations. Tetrahedron 1992, 48, 4587-4592.

(8) Kirk, O.; Christensen, M. W.; Damhus, T.; Godtfredsen, S. E. Enzyme catalyzed degradation and formation of peroxycarboxylic acids. Biocatalysis 1994, 11, 65-77.

(9) Piazza, G. J.; Nuñez, A.; Foglia, T. A. Epoxidation of fatty acids, fatty methyl esters, and alkenes by immobilized oat seed peroxygenase. J. Mol. Catal. B-Enzym. 2003, 21, 143-151.

(10) Hamberg, M.; Fahlstadius, P. On the specificity of a fatty acid epoxygenase in broad bean (Vicia faba L.). Plant Physiol. 1992, 99, 987-995.

(11) Oliw, E. H. Oxygenation of polyunsaturated fatty acids by cytochrome P450 monooxygenates. Progr. Lipid Res. 1994, 33, 329354.

(12) Ruettinger, R. T.; Fulco, A. J. Epoxidation of unsaturated fattyacids by a soluble cytochrome P-450-dependent system from Bacillus megaterium. J. Biol. Chem. 1981, 256, 5728-5734.

(13) Munro, A. W.; Leys, D. G.; McLean, K. J.; Marshall, K. R.; Ost, T. W. B.; Daff, S.; Miles, C. S.; Chapman, S. K.; Lysek, D. A.; Moser, C. C.; Page, C. C.; Dutton, P. L. P450BM3: the very model of a modern flavocytochrome. Trends Biochem. Sci. 2002, 27, 250-257.

(14) Munro, A. W.; McLean, K. J.; Grant, J. L.; Makris, T. M. Structure and function of the cytochrome $\mathrm{P} 450$ peroxygenase enzymes. Biochem. Soc. Trans. 2018, 46, 183-196.

(15) Hofrichter, M.; Kellner, H.; Pecyna, M. J.; Ullrich, R. Fungal unspecific peroxygenases: Heme-thiolate proteins that combine peroxidase and cytochrome $\mathrm{P} 450$ properties. Adv. Exp. Med. Biol. 2015, 851, 341-368.

(16) Hofrichter, M.; Kellner, H.; Herzog, R.; Karich, A.; Liers, C.; Scheibner, K.; Wambui, V.; Ullrich, R. Fungal peroxygenases: A 
phylogenetically old superfamily of heme enzymes with promiscuity for oxygen transfer reactions; In Grand challenges in fungal biotechnology; Nevalainen, H., Ed.; Springer: Cham, Switzerland, 2020, pp. 369-403.

(17) Ullrich, R.; Nüske, J.; Scheibner, K.; Spantzel, J.; Hofrichter, M. Novel haloperoxidase from the agaric basidiomycete Agrocybe aegerita oxidizes aryl alcohols and aldehydes. Appl. Environ. Microbiol. 2004, 70, 4575-4581.

(18) Wang, Y.; Lan, D.; Durrani, R.; Hollmann, F. Peroxygenases en route to becoming dream catalysts. What are the opportunities and challenges? Curr. Opin. Chem. Biol. 2017, 37, 1-9.

(19) Peter, S.; Kinne, M.; Wang, X.; Ullrich, R.; Kayser, G.; Groves, J. T.; Hofrichter, M. Selective hydroxylation of alkanes by an extracellular fungal peroxygenase. FEBS J. 2011, 278, 3667-3675.

(20) Olmedo, A.; Aranda, C.; del Río, J. C.; Kiebist, J.; Scheibner, K.; Martínez, A. T.; Gutiérrez, A. From alkanes to carboxylic acids: Terminal oxygenation by a fungal peroxygenase. Angew. Chem., Int. Ed. 2016, 55, 12248-12251.

(21) Gutiérrez, A.; Babot, E. D.; Ullrich, R.; Hofrichter, M.; Martínez, A. T.; del Río, J. C. Regioselective oxygenation of fatty acids, fatty alcohols and other aliphatic compounds by a basidiomycete heme-thiolate peroxidase. Arch. Biochem. Biophys. 2011, 514, 33-43.

(22) Barková, K.; Kinne, M.; Ullrich, R.; Hennig, L.; Fuchs, A.; Hofrichter, M. Regioselective hydroxylation of diverse flavonoids by an aromatic peroxygenase. Tetrahedron 2011, 67, 4874-4878.

(23) Babot, E. D.; del Río, J. C.; Kalum, L.; Martínez, A. T.; Gutiérrez, A. Regioselective hydroxylation in the production of 25hydroxyvitamin D by Coprinopsis cinerea peroxygenase. ChemCatChem 2015, 7, 283-290.

(24) Babot, E. D.; del Río, J. C.; Cañellas, M.; Sancho, F.; Lucas, F.; Guallar, V.; Kalum, L.; Lund, H.; Gröbe, G.; Scheibner, K.; Ullrich, R.; Hofrichter, M.; Martínez, A. T.; Gutiérrez, A. Steroid hydroxylation by basidiomycete peroxygenases: A combined experimental and computational study. Appl. Environ. Microbiol. 2015, 81, $4130-4142$

(25) Aranda, C.; Ullrich, R.; Kiebist, J.; Scheibner, K.; del Río, J. C.; Hofrichter, M.; Martínez, A. T.; Gutierrez, A. Selective synthesis of the resveratrol analogue 4,4'-dihydroxy-trans-stilbene and stilbenoids modification by fungal peroxygenases. Catal. Sci. Technol. 2018, 8, 2394-2401.

(26) Aranda, C.; Municoy, M.; Guallar, V.; Kiebist, J.; Scheibner, K.; Ullrich, R.; del Río, J. C.; Hofrichter, M.; Martínez, A. T.; Gutiérrez, A. Selective synthesis of 4-hydroxyisophorone and 4-ketoisophorone by fungal peroxygenases. Catal. Sci. Technol. 2019, 9, 1398-1405.

(27) Babot, E. D.; Aranda, C.; del Río, J. C.; Ullrich, R.; Kiebist, J.; Scheibner, K.; Hofrichter, M.; Martínez, A. T.; Gutiérrez, A. Selective oxygenation of ionones and damascones by fungal peroxygenases. $J$. Agric. Food Chem. 2020, 68, 5375-5383.

(28) Kinne, M.; Poraj-Kobielska, M.; Aranda, E.; Ullrich, R.; Hammel, K. E.; Scheibner, K.; Hofrichter, M. Regioselective preparation of 5-hydroxypropranolol and 4 '-hydroxydiclofenac with a fungal peroxygenase. Bioorg. Medicinal Chem. Lett. 2009, 19, 30853087.

(29) Poraj-Kobielska, M.; Kinne, M.; Ullrich, R.; Scheibner, K.; Kayser, G.; Hammel, K. E.; Hofrichter, M. Preparation of human drug metabolites using fungal peroxygenases. Biochem. Pharmacol. 2011, 82, 789-796.

(30) Gómez de Santos, P.; Cañellas, M.; Tieves, F.; Younes, S. H. H.; Molina-Espeja, P.; Hofrichter, M.; Hollmann, F.; Guallar, V.; Alcalde, M. Selective synthesis of the human drug metabolite 5hydroxypropranolol by an evolved self-sufficient peroxygenase. ACS Catal. 2018, 8, 4789-4799.

(31) Kiebist, J.; Hofrichter, M.; Zuhse, R.; Scheibner, K. Oxyfunctionalization of pharmaceuticals by fungal peroxygenases; In Pharmaceutical biocatalysis: Chemoenzymatic synthesis of active pharmaceutical ingredients, chapter 18; Grunwald, P., Ed.; Jenny Stanford Publishing: Singapore, 2020, pp. 643-680.
(32) Carro, J.; Ferreira, P.; Rodríguez, L.; Prieto, A.; Serrano, A.; Balcells, B.; Ardá, A.; Jiménez-Barbero, J.; Gutiérrez, A.; Ullrich, R.; Hofrichter, M.; Martínez, A. T. 5-Hydroxymethylfurfural conversion by fungal aryl-alcohol oxidase and unspecific peroxygenase. FEBS $J$. 2015, 282, 3218-3229.

(33) Olmedo, A.; del Río, J. C.; Kiebist, J.; Ullrich, R.; Hofrichter, M.; Scheibner, K.; Martínez, A. T.; Gutiérrez, A. Fatty acid chain shortening by a fungal peroxygenase. Chem. - Eur. J. 2017, 23, 16985-16989.

(34) Ullrich, R.; Poraj-Kobielska, M.; Scholze, S.; Halbout, C.; Sandvoss, M.; Pecyna, M. J.; Scheibner, K.; Hofrichter, M. Side chain removal from corticosteroids by unspecific peroxygenase. J. Inorg. Biochem. 2018, 183, 84-93.

(35) Hofrichter, M.; Ullrich, R. Oxidations catalyzed by fungal peroxygenases. Curr. Opin. Chem. Biol. 2014, 19, 116-125.

(36) Karich, A.; Kluge, M.; Ullrich, R.; Hofrichter, M. Benzene oxygenation and oxidation by the peroxygenase of Agrocybe aegerita. AMB Express 2013, 3, 5.

(37) Kinne, M.; Zeisig, C.; Ullrich, R.; Kayser, G.; Hammel, K. E.; Hofrichter, M. Stepwise oxygenations of toluene and 4-nitrotoluene by a fungal peroxygenase. Biochem. Biophys. Res. Commun. 2010, 397, $18-21$.

(38) Ullrich, R.; Dolge, C.; Kluge, M.; Hofrichter, M. Pyridine as novel substrate for regioselective oxygenation with aromatic peroxygenase from Agrocybe aegerita. FEBS Lett. 2008, 582, 41004106.

(39) Aranda, E.; Ullrich, R.; Hofrichter, M. Conversion of polycyclic aromatic hydrocarbons, methyl naphthalenes and dibenzofuran by two fungal peroxygenases. Biodegradation 2010, 21, 267-281.

(40) Aranda, C.; Olmedo, A.; Kiebist, J.; Scheibner, K.; del Río, J. C.; Martínez, A. T.; Gutiérrez, A. Selective epoxidation of fatty acids and fatty acid methyl esters by fungal peroxygenases. ChemCatChem 2018, 10, 3964-3968.

(41) Peter, S.; Kinne, M.; Ullrich, R.; Kayser, G.; Hofrichter, M. Epoxidation of linear, branched and cyclic alkenes catalyzed by unspecific peroxygenase. Enzyme Microb. Technol. 2013, 52, 370-376.

(42) Petrović, Z. S. Polyurethanes from vegetable oils. Polym. Rev. 2008, 48, 109-155.

(43) González-Benjumea, A.; Carro, J.; Renau-Mínguez, C.; Linde, D.; Fernández-Fueyo, E.; Gutiérrez, A.; Martínez, A. T. Fatty acid epoxidation by Collariella virescens peroxygenase and heme-channel variants. Catal. Sci. Technol. 2020, 10, 717-725.

(44) Carro, J.; González-Benjumea, A.; Fernández-Fueyo, E.; Aranda, C.; Guallar, V.; Gutiérrez, A.; Martínez, A. T. Modulating fatty acid epoxidation $v s$ hydroxylation in a fungal peroxygenase. ACS Catal. 2019, 9, 6234-6242.

(45) Linde, D.; Olmedo, A.; González-Benjumea, A.; Estévez, M.; Renau-Mínguez, C.; Carro, J.; Fernández-Fueyo, E.; Gutiérrez, A.; Martínez, A. T. Two new unspecific peroxygenases from heterologous expression of fungal genes in Escherichia coli. Appl. Environ. Microbiol. 2020, 86 doi: DOI: 10.1128/AEM.02899-19.

(46) Piontek, K.; Strittmatter, E.; Ullrich, R.; Gröbe, G.; Pecyna, M. J.; Kluge, M.; Scheibner, K.; Hofrichter, M.; Plattner, D. A. Structural basis of substrate conversion in a new aromatic peroxygenase: Cytochrome P450 functionality with benefits. J. Biol. Chem. 2013, 288, 34767-34776.

(47) Lucas, F.; Babot, E. D.; Cañellas, M.; del Río, J. C.; Kalum, L.; Ullrich, R.; Hofrichter, M.; Guallar, V.; Martínez, A. T.; Gutiérrez, A. Molecular determinants for selective $C_{25}$-hydroxylation of vitamins $D_{2}$ and $\mathrm{D}_{3}$ by fungal peroxygenases. Catal. Sci. Technol. 2016, 6, 288295.

(48) Lecina, D.; Gilabert, J. F.; Guallar, V. Adaptive simulations, towards interactive protein-ligand modeling. Sci. Rep. 2017, 7, 8466.

(49) Ullrich, R.; Hofrichter, M. The haloperoxidase of the agaric fungus Agrocybe aegerita hydroxylates toluene and naphthalene. FEBS Lett. 2005, 579, 6247-6250.

(50) Babot, E. D.; del Río, J. C.; Kalum, L.; Martínez, A. T.; Gutiérrez, A. Oxyfunctionalization of aliphatic compounds by a 
recombinant peroxygenase from Coprinopsis cinerea. Biotechnol. Bioeng. 2013, 110, 2332.

(51) Karich, A.; Scheibner, K.; Ullrich, R.; Hofrichter, M. Exploring the catalase activity of unspecific peroxygenases and the mechanism of peroxide-dependent heme destruction. J. Mol. Catal. B-Enzym. 2016, 134, 238-246.

(52) Monza, E.; Lucas, M. F.; Camarero, S.; Alejaldre, L. C.; Martínez, A. T.; Guallar, V. Insights on laccase engineering from molecular simulations: towards a binding-focused strategy. J. Phys. Chem. Lett. 2015, 6, 1447-1453.

(53) Carro, J.; Amengual-Rigo, P.; Sancho, F.; Medina, M.; Guallar, V.; Ferreira, P.; Martínez, A. T. Multiple implications of an active site phenylalanine in the catalysis of aryl-alcohol oxidase. Sci. Rep. 2018, 8, 8121.

(54) Çelik, A.; Sperandio, D.; Speight, R. E.; Turner, N. J. Enantioselective epoxidation of linolenic acid catalysed by cytochrome P450BM3 from Bacillus megaterium. Org. Biomol. Chem. 2005, 3, 2688-2690.

(55) Falck, J. R.; Reddy, Y. K.; Haines, D. C.; Reddy, K. M.; Krishna, U. M.; Graham, S.; Murry, B.; Peterson, J. A. Practical, enantiospecific syntheses of 14,15-EET and leukotoxin B (vernolic acid). Tetrahedron Lett. 2001, 42, 4131-4133.

(56) Klaas, M. R. G.; Warwel, S. Complete and partial epoxidation of plant oils by lipase-catalyzed perhydrolysis. Ind. Crops Prod. 1999, 9, $125-132$.

(57) Orellana-Coca, C.; Adlercreutz, D.; Andersson, M. M.; Mattiasson, B.; Hatti-Kaul, R. Analysis of fatty acid epoxidation by high performance liquid chromatography coupled with evaporative light scattering detection and mass spectrometry. Chem. Phys. Lipids 2005, 135, 189-199.

(58) Muturi, P.; Wang, D.; Dirlikov, S. Epoxidized vegetable oils as reactive diluents I. Comparison of vernonia, epoxidized soybean and epoxidized linseed oils. Progr. Org. Coatings 1994, 25, 85-94.

(59) Kato, T.; Yamaguchi, Y.; Hirano, T.; Yokoyama, T.; Uyehara, T.; Namai, T.; Yamanaka, S.; Harada, N. Unsaturated hydroxy fatty acids, the self defensive substances in rice plant against rice blast disease. Chem. Lett. 1984, 13, 409-412.

(60) Kato, T.; Nakai, T.; Ishikawa, R.; Karasawa, A.; Namai, T. Preparation of the enantiomers of hydroxy-C18 fatty acids and their anti-rice blast fungus activities. Tetrahedron: Asymmetry 2001, 12, 2695-2701.

(61) Namai, T.; Kato, T.; Yamaguchi, Y.; Hirukawa, T. Anti-rice blast activity and resistance induction of C-18 oxygenated fatty acids. null 1993, 57, 611-613.

(62) Sisignano, M.; Steinhilber, D.; Parnham, M. J.; Geisslinger, G. Exploring CYP2J2: lipid mediators, inhibitors and therapeutic implications. Drug Dis. Today 2020, 1744.

(63) Ozawa, T.; Nishikimi, M.; Sugiyama, S.; Taki, F.; Hayakawa, M.; Shionoya, H. Cytotoxic activity of leukotoxin, a neutrophilderived fatty acid epoxide, on cultured human cells. Biochem. Int. 1988, 16, 369-373.

(64) Murray, M.; Hraiki, A.; Bebawy, M.; Pazderka, C.; Rawling, T. Anti-tumor activities of lipids and lipid analogues and their development as potential anticancer drugs. Pharmacol. Ther. 2015, $150,109-128$.

(65) Carlson, K. D.; Schneider, W. J.; Chang, S. D.; Princen, L. H. Vernonia galamensis seed oil-a new source for epoxy coatings; In New sources of fats and oils; Pryde, E. H.; Princen, L. H.; Mukherjee, K. D., Eds.; AOCS: Champaign, 1981, pp. 297-318.

(66) Ishizaki, T.; Ozawa, T.; Voelkel, N. F. Leukotoxins and the lung. Pulm. Pharmacol. Ther. 1999, 12, 145-155.

(67) Chaudhry, A.; Kleiman, R.; Carlson, K. D. Minor components of Lesquerella fendleri seed oil. J. Amer. Oil Chem. Soc. 1990, 67, 863866.

(68) Johnston, J. B.; Ouellet, H.; Podust, L. M.; de Montellano, P. R. O. Structural control of cytochrome P450-catalyzed w-hydroxylation. Arch. Biochem. Biophys. 2011, 507, 86-94.

(69) Kahn, R. A.; Le Bouquin, R.; Pinot, F.; Benveniste, I.; Durst, F. A conservative amino acid substitution alters the regiospecificity of
CYP94A2, a fatty acid hydroxylase from the plant Vicia sativa. Arch. Biochem. Biophys. 2001, 391, 180-187.

(70) Hammerer, L.; Winkler, C. K.; Kroutil, W. Regioselective biocatalytic hydroxylation of fatty acids by cytochrome P450s. Catal. Lett. 2018, 148, 787-812.

(71) de Montellano, P. R. O., Cytochrome P450: Structure, mechanism, and biochemistry; Springer: NY, 912 pp, 2015.

(72) Girvan, H. M.; Munro, A. W. Applications of microbial cytochrome P450 enzymes in biotechnology and synthetic biology. Curr. Opin. Chem. Biol. 2016, 31, 136-145.

(73) Molina-Espeja, P.; Cañellas, M.; Plou, F. J.; Hofrichter, M.; Lucas, F.; Guallar, V.; Alcalde, M. Synthesis of 1-naphthol by a natural peroxygenase engineered by directed evolution. ChemBioChem 2016, 17, 341-349.

(74) Hobisch, M.; Holtmann, D.; Gomez de Santos, P.; Alcalde, M.; Hollmann, F.; Kara, S. Recent developments in the use of peroxygenases- Exploring their high potential in selective oxyfunctionalisations. Biotechnol. Adv. 2020, 107615.

(75) Sigmund, M. C.; Poelarends, G. J. Current state and future perspectives of engineered and artificial peroxygenases for the oxyfunctionalization of organic molecules. Nat. Catal. 2020, 3, $690-702$.

(76) Ullrich, R.; Karich, A.; Hofrichter, M. Fungal peroxygenases - A versatile tool for biocatalysis; In Reference Module in Life Sciences, 21067; Elsevier: DOI: 10.1016/B978-0-12-809633-8.21067-4, 2020.

(77) Schrödinger, Release 2019-1: Prime; LLC: New York, 2019.

(78) Altschul, S. F.; Gish, W.; Miller, W.; Myers, E. W.; Lipman, D. J. Basic local alignment search tool. J. Mol. Biol. 1990, 215, 403-410.

(79) Sastry, G. M.; Adzhigirey, M.; Day, T.; Annabhimoju, R.; Sherman, W. Protein and ligand preparation: parameters, protocols, and influence on virtual screening enrichments. J. Comput.-Aided Mol. Des. 2013, 27, 221-234.

(80) Schrödinger; QSite 5.7; LCC: New York, 2011.

(81) Gilabert, J. F.; Lecina, D.; Estrada, J.; Guallar, V. Monte Carlo techniques for drug design: The success case of PELE; In Biomolecular simulations in drug discovery; Gervasio, F. L.; Spiwok, V., Eds.; Wiley: 2018, pp. 87-96.

(82) Otey, C. R. High-throughput carbon monoxide binding assay for cytochromes P450. Methods Mol. Biol. 2003, 230, 137-139.

(83) Puigbó, P.; Guzmán, E.; Romeu, A.; García-Vallve, S. OPTIMIZER: a web server for optimizing the codon usage of DNA sequences. Nucleic Acids Res. 2007, 35, W126-W131.

(84) Studier, F. W. Protein production by auto-induction in highdensity shaking cultures. Protein Expression Purif. 2005, 41, 207-234. 